\title{
Climate Warming Changed the Planting Boundaries of Varieties of Summer Corn with Different Maturity Levels in the North China Plain
}

\author{
Qi Hu, Xueqing Ma, Xuebiao Pan, and Huang BinXiang \\ College of Resources and Environmental Sciences, China Agricultural University, Beijing, and Inner Mongolia Ecological and \\ Agricultural Meteorology Center, Inner Mongolia Meteorological Bureau, Hohhot, Inner Mongolia, China
}

(Manuscript received 8 March 2019, in final form 6 October 2019)

\begin{abstract}
Climate warming in the North China Plain (NCP) is expected to greatly affect corn production. On the basis of a comprehensive consideration of the double-cropping system, we investigated the impacts of climate warming in the past 55 years on the planting boundaries and areas of varieties of summer corn with different maturity levels. In addition, we tried to explore the probable reasons for the changes in planting boundaries. Climate warming caused a northward shift in the planting boundaries of summer corn, resulting in the expansion of the total planting area. However, the trend for the planting area of each belt of corn maturity was not always consistent. Because of the advanced planting date and delayed physiological maturation date, the growing season of corn in the NCP has been prolonged in the past 55 years. Climate warming also increased the active accumulated temperature with a threshold of $10^{\circ}$ (AAT10) during the corn growing season by $73.2^{\circ} \mathrm{C}_{\text {decade }}^{-1}$, which was mainly caused by the increase in the number of days with a daily temperature over $10^{\circ} \mathrm{C}$. In summary, the planting boundaries of varieties of summer corn with different maturity levels have greatly changed due to climate change, and corn production in the NCP could benefit from climate warming through the greater planting area and longer growing season.
\end{abstract}

\section{Introduction}

For the past 60 years, climate change marked by global warming has definitely occurred (Vaughan et al. 2003). The Intergovernmental Panel on Climate Change (IPCC) confirmed that Earth surface's air temperature increased by approximately $0.6^{\circ} \pm 0.2^{\circ} \mathrm{C}$ during the twentieth century (IPCC 2013). In China, climate warming is more pronounced, with a temperature increase of $0.27^{\circ} \mathrm{C}$ decade $^{-1}$ over the past five decades, and North China showed an obviously higher warming trend compared with that observed in South China ( $\mathrm{Hu}$ et al. 2014). The North China Plain (NCP), as one of the major grain production bases ( $\mathrm{Li}$ et al. 2007; Luo et al. 2015), plays a vital role in China's food production and security. This critical role is because the single-year winter wheat (Triticum aestivum L.) and summer corn (Zea mays L.) rotation dominates the agronomic cropping system (He et al. 2009; Cui et al. 2010), and the NCP produces over $50 \%$ of the nation's wheat and $33.3 \%$ of the corn yield (Wang et al. 2012). However, in the NCP, corn and wheat production are vulnerable to climate

\footnotetext{
Corresponding author: Huang Binxiang, bxhuang@cau.edu.cn
}

variability and climate change (Tao et al. 2006; Chen et al. 2010), as their phonological development and productivity are significantly impacted by heat resources (Parry et al. 2004; Siebert et al. 2014).

Many studies have confirmed that climate warming has greatly influenced global crop production since the 1980s (Lobell et al. 2011; Zhang et al. 2016), and cropping systems are also affected (Dong et al. 2009; Yang et al. 2011). Xiao and Tao reported that crop yield in the NCP declined by $15 \%-30 \%$ in $1981-2009$ due to the trends in climate variables (Xiao and Tao 2016). Corn yield is predicted to decrease by $13.2 \%-19.1 \%$ in the future if no adaptation measures are taken (Tao and Zhang 2010). Rising temperatures are expected to accelerate the crop processes of growth and development (Rötter and van de Geijn 1999; Bonfante et al. 2015), thus consequently shortening the length of the reproductive growth stage (Easterling et al. 1997; Xiao et al. 2016) and reducing the total dry biomass. On the other hand, climate warming allows the threshold temperature needed to start plant growth to occur sooner, which could extend the geographical distribution and provide a longer growing season for some agricultural crops (Todd 1996; Porter 2005). Therefore, the negative effects on 
crop production caused by climate warming could be offset by adapting later-maturing crop cultivars and improving management (Olesen et al. 2011; Y. Liu et al. 2013; Bu et al. 2015). The NCP is expected to benefit more from climate warming because the single-year wheat-corn cropping system in the northern NCP is strictly limited by the amount of thermal time. Xiao et al. (2016) highlighted that, by obtaining more heat resources, shifting cultivars in longer growth periods compensated for the negative impact of climate change in the NCP. Liu et al. (2010) further showed that new corn varieties helped stabilize the length of the preflowering period and also extended the grain-filling period, which resulting in an increased corn yield.

In application, the planting boundaries of varieties of summer corn with different maturity levels in the NCP must be defined, which could guide farmers adopt suitable corn maturity varieties in different regions. However, previous studies have mainly analyzed the changes in planting boundaries or shifted cropping areas of a single-cropping system, such as spring corn (Y. Liu et al. 2013), winter wheat (Jin et al. 2002; Yi et al. 2013), and rice (Yun et al. 2005; Xia et al. 2014), in Northeast China. Few researchers have focused on the changes in the planting boundaries of summer corn with different maturity levels, particularly in relation to the wheatcorn double-cropping system in the NCP. Therefore, the spatiotemporal distribution and variation in the possible cultivation area of each type of summer corn maturation level, based on the wheat-corn cropping system in the NCP, were investigated in this study. The objectives are 1) to clarify the distribution of the maturity belts of summer corn in the past 55 years in the NCP and 2) to determine the variations in planting boundaries and areas of each belt of corn maturity due to climate warming. In addition, we tried to quantitatively explore the probable reasons explaining the changes in planting boundaries by analyzing the growing days and thermal conditions during the corn growing season.

\section{Methods}

\section{a. Study area}

The NCP is the largest national alluvial plain, as the Yellow River flows through the middle of the plain into the Bohai Sea. The study area involves two provincelevel municipalities (i.e., Beijing and Tianjin) and three provinces (i.e., Hebei, Shandong, and Henan), with a total land area of $53.66 \times 10^{4} \mathrm{~km}^{2}$; the study area is found within $110^{\circ} 51^{\prime}-122^{\circ} 04^{\prime} \mathrm{E}$ and $31^{\circ} 56^{\prime}-42^{\circ} 73^{\prime} \mathrm{N}$ (Fig. 1). Two mountain systems, named the Yan Mountains and Taihang Mountains, lie in the northern and western margins of the NCP, respectively. Because the NCP is located in the East Asian temperate monsoon climate zone, it has a typical temperate and monsoonal climate characterized by dry and windy winters and hot and rainy summers (Kreuzer et al. 2004). The long-term average annual air temperature ranges from $8^{\circ}$ to $15^{\circ} \mathrm{C}$ (Chen 2017), the frost-free period is approximately 200 days, and the total annual sunshine duration is 1910.6-2982.9h (Chen 2012). The annual rainfall ranges from 500 to $1000 \mathrm{~mm}$, with nearly $70 \%$ of annual precipitation occurring from July to September (Zhang et al. 2005), and the amount of precipitation gradually increases from the northwest to the southeast.

\section{b. Technique description}

\section{1) Meteorological data}

Daily air temperature data from 61 meteorological stations, each with a 55-yr data record (from 1961 to 2015), were used in this study. The spatial distribution of the stations is shown in Fig. 1. The datasets were provided by the China Meteorological Data Sharing Service Network (http://data.cma.cn/). Because the quality of the original dataset was strictly tested and controlled, the temperature datasets have less than $0.1 \%$ of missing values. All missing data were filled using the linear interpolation method.

\section{2) $\mathrm{AAT}$}

Thermal conditions are expected to play a significant role in regulating crop growth (Dong et al. 2009) and productivity (Bunting 1976). The active accumulated temperature (AAT; ${ }^{\circ} \mathrm{C}$ ) is the sum of the daily mean temperatures above a given threshold temperature (Schoenau and Kehrig 1990); this variable was first introduced to agricultural meteorology as an indicator of thermal conditions in England (Hou et al. 2014). As an effective method for describing the thermal conditions of biological growth and development (Chezik et al. 2014), the AAT has been widely applied to many crops, including corn (Harrison et al. 2011), rice (Murakami et al. 2009; Huang et al. 2016), and wheat (Mcmaster and Wilhelm 1998). Bunting (1979) reported that an AAT with a threshold temperature of $10^{\circ} \mathrm{C}$ (AAT10) showed a strong relationship with corn development and yield in Europe and America. In China, the AAT has been routinely used to study crop physiological ecology (Bai et al. 2008) and to analyze cropping systems and crop variety boundaries (Liu et al. 2010). In this study, the AAT10 was determined by summing the daily temperature values from the planting date to the physiological maturation date on which the daily mean temperature was over $10^{\circ} \mathrm{C}$ (DT10): 

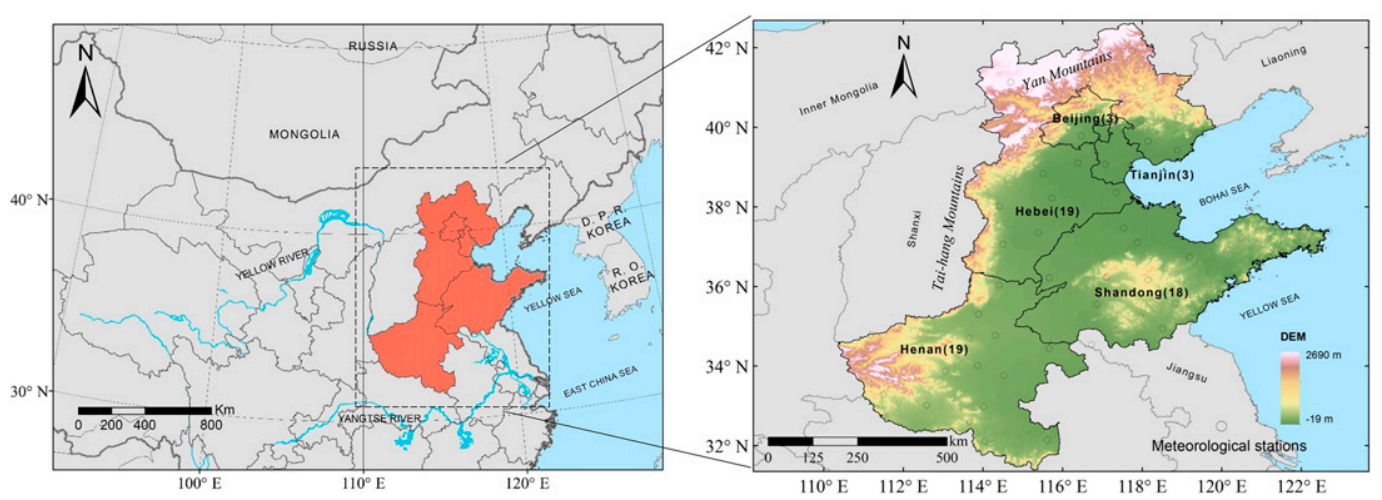

FIG. 1. Boundary and meteorological stations in the NCP. Digital elevation model data were from the Chinese Academy of Sciences (http://www.resdc.cn/).

$$
\mathrm{AAT} 10=\sum_{i=a}^{b} T_{i} \text { for } \quad T_{i} \geq 10,
$$

where $T_{i}\left({ }^{\circ} \mathrm{C}\right)$ is the daily mean air temperature on the $i$ th day, and $a$ and $b$ are the starting and ending dates of DT10, respectively.

Previous studies have frequently reported that corn requires a certain thermal time to obtain physiological maturity (Sprague and Dudley 1988). The AAT10, as a simple and effective maturity index, has been widely adopted to better classify corn maturity groups. As the distribution of maize in North China is mainly limited by heat, Fang et al. proposed a classification of summer-corn maturity in the NCP by using the growth period and the AAT10 (Fang et al. 2010), as shown in Table 1. Summer corn can be divided into five maturity belts-A: very early ripe belt, B: early ripe belt, C: midripe belt, D: late ripe belt, and $\mathrm{E}$ : very late ripe belt.

\section{3) GROWTH PERIOD OF SUMMER CORN}

Because summer corn is planted in rotation with winter wheat in the $\mathrm{NCP}$, the planting date and harvesting date of wheat must be considered when determining the growth season of summer corn. The wheat-corn intercropping technology was popular in the 1990s in the northern NCP, where the thermal time was insufficient for a single-year wheat-corn cropping system (Wang 2009). Using intercropping technology, corn was intercropped into wheat fields $10-15$ days before wheat was harvested; this method allowed the corn to receive more heat for physiological maturity before wheat was planted in autumn. However, in the past decade, farmers in the NCP have seldom intercropped wheat with corn, partly because of climate warming and partly because of the reduced agricultural labor force. Since no recorded data with long time series (1961-2015) were available (actually, we can only obtain the data since 1990), the planting date and harvesting date of summer corn was theoretical estimated without considering the intercropping, and the calculation procedure is shown in Fig. 2.

The planting date and harvesting date of winter wheat were first calculated in the NCP. Li et al. (2010) reported that the required AAT over $0^{\circ} \mathrm{C}$ (AAT0) from the planting date to the beginning date of the overwintering period was approximately $600^{\circ} \mathrm{C}$ for winter wheat in the NCP. In agrometeorology, the first-frost date is the beginning day of the overwintering period of winter wheat, which was determined using a five-day moving average of daily mean temperature $<0^{\circ} \mathrm{C}$ in $1961-2015$ in the NCP. Therefore, we set the first-frost date as the starting point and aggregated the daily temperature backward from the starting point until the AAT0 reached $600^{\circ} \mathrm{C}$, and then the corresponding date was determined as the planting date of winter wheat (Fig. 2).

Similarly, winter wheat required an AAT0 value of $2200^{\circ} \mathrm{C}$ from the reviving stage to physiological maturity (Yang et al. 2009; Li et al. 2012). The last-frost date is the

TABLE 1. The classification of summer-corn maturity on the basis of growth period and AAT10 in the NCP.

\begin{tabular}{lccccc}
\hline \hline \multicolumn{1}{c}{ Maturity groups } & A: very early ripe & B: early ripe & C: midripe & D: late ripe & E: very late ripe \\
\hline Growth period (days) & $<85$ & $85-95$ & $96-105$ & $106-115$ & $>115$ \\
AAT10 $\left({ }^{\circ} \mathrm{C}\right)^{\mathrm{a}}$ & $1800-2000$ & $2000-2200$ & $2200-2400$ & $2400-2600$ & $2600-2800$ \\
\hline
\end{tabular}

${ }^{\text {a }}$ AAT10 = mean temperature summed up for each day from planting to physiological maturity. A daily mean temperature lower than $10^{\circ} \mathrm{C}$ resulted in the use of $0^{\circ} \mathrm{C}$. 


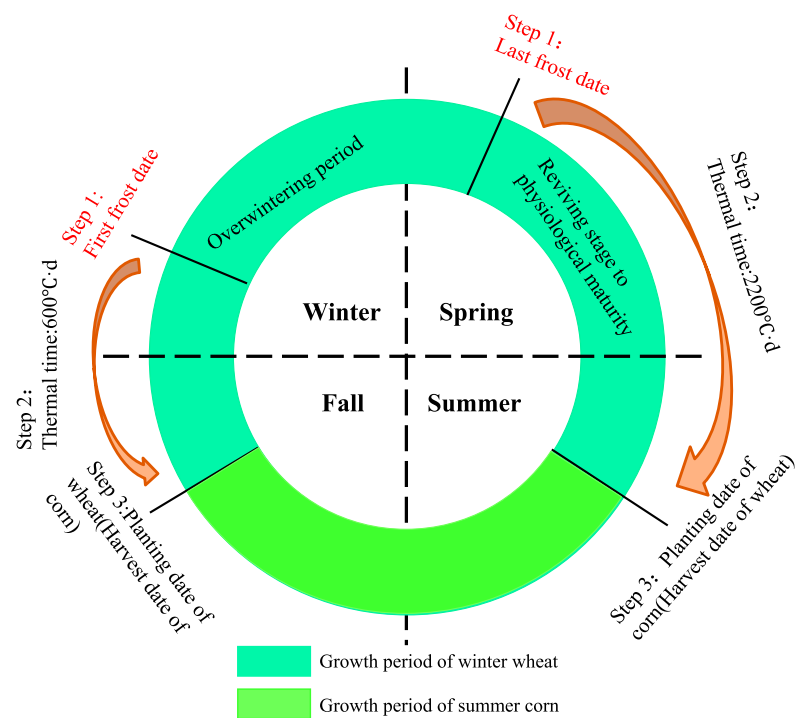

FIG. 2. Calculation procedure for determining the planting date and harvesting date of summer corn in the single-year wheat-corn cropping system in the NCP. The last and first frost dates were first calculated (step 1 ) on the basis of the daily average temperature data. Then, the wheat planting date was determined by aggregating the daily temperature backward from the first frost date until the AAT0 reached $600^{\circ} \mathrm{C}$ and the wheat harvesting date was determined by aggregating the daily temperature backward from the last frost date until the AAT0 reached $2200^{\circ} \mathrm{C}$ (step 2). In step 3, the planting date of summer corn was determined as the date 2 days after winter wheat was harvested and the harvesting date of summer corn was determined as the date 2 days before winter wheat was planted.

beginning day of the reviving stage of winter wheat, and the harvesting date of winter wheat was determined by aggregating the daily temperature backward from the last-frost date until the AAT0 reached $2200^{\circ} \mathrm{C}$.

Experimental data from 14 agricultural trial sites in the study area were used to compare the theoretical planting and harvesting dates of wheat with the actual ones (Table 2). The result showed that nonsignificant differences were found between the theoretical planting (harvesting) dates and the actual dates.

Considering the factors of machinery and labor force in actual production, we set up two days as the harvestplant time, that is, the planting date of summer corn was determined as the date two days after winter wheat was harvested, and the harvesting date of summer corn was determined as the date two days before winter wheat was planted.

\section{4) Climate trend}

In this study, the trend value for a climatic variable $X$ was calculated using a linear regression equation as follows:

$$
X=a t+b, \quad t=1,2,3, \ldots, n,
$$

where $a$ is the linear slope, $b$ is the $y$-axis intercept value, $t$ is the number of years, and $n$ is the length of the date record and is equal to 55 in our study (i.e., 1961-2015) The climate trend value ( $\beta$; value per decade) is equal to $a \times 10$. A positive or negative $\beta$ value indicates an increasing or decreasing trend, respectively. The $F$-test method was used to analyze the significance of the regression equation, with the level of significance of $p<0.05$.

MATLAB 2014 software was used for data processing and calculation. Because it is difficult to identify regional patterns based on only the individual stations, spatial analysis was also used to explore the regional changes. All spatial distribution maps (Figs. 1, 3, 4, 6, and 9 , described in more detail below) were constructed using the inverse-distance-weighting interpolation method embedded in the ArcGIS 10.1 software package with a grid cell size of $0.02^{\circ}$ (approximately $2 \mathrm{~km}$ ).

TABLE 2. Comparison of theoretical sowing and harvesting dates with actual dates of winter wheat at different agricultural trial sites.

\begin{tabular}{lcrrrr}
\hline \hline $\begin{array}{l}\text { Agricultural } \\
\text { trial site }\end{array}$ & Years & Theoretical sowing & Actual sowing \\
date & \multicolumn{1}{c}{$\begin{array}{c}\text { Theoretical harvesting } \\
\text { date }\end{array}$} & $\begin{array}{c}\text { Actual harvesting } \\
\text { date }\end{array}$ \\
\hline Zunhua & $1994-2010$ & $275.9 \pm 3.8$ & $273.6 \pm 3.3$ & $166.7 \pm 3.3$ & $168.9 \pm 2.3$ \\
Langfang & $2003-13$ & $277 \pm 3.4$ & $280.6 \pm 3.4$ & $162.1 \pm 3.2$ & $162.5 \pm 3.5$ \\
Baodi & $1992-2013$ & $274.6 \pm 4.2$ & $274.9 \pm 3.1$ & $167.1 \pm 3.3$ & $166 \pm 2.5$ \\
Huanghua & $1992-2013$ & $279.6 \pm 3.4$ & $277.2 \pm 7.3$ & $164.1 \pm 3.5$ & $157.2 \pm 3.9$ \\
Huiminxian & $1992-2013$ & $278.3 \pm 4.0$ & $283 \pm 2.6$ & $163.7 \pm 3.3$ & $161.7 \pm 4.6$ \\
Weifang & $1992-2013$ & $278.2 \pm 3.6$ & $274.7 \pm 5.1$ & $169.4 \pm 3.8$ & $160.8 \pm 4.4$ \\
Anyang & $2011-13$ & $286.7 \pm 1.2$ & $287 \pm 3.0$ & $153.5 \pm 1.4$ & $153.5 \pm 1.2$ \\
Xinxiang & $1995-2013$ & $282.6 \pm 3.9$ & $282.5 \pm 3.5$ & $152.8 \pm 4.4$ & $152.1 \pm 3.8$ \\
Zhengzhou & $1992 ; 1995-2013$ & $287.0 \pm 4.6$ & $288.4 \pm 3.9$ & $151.6 \pm 5.6$ & $150.2 \pm 3.7$ \\
Xuchang & $1992-2000 ; 2003-13$ & $286.9 \pm 5.3$ & $283.3 \pm 4.0$ & $155.1 \pm 5.5$ & $150.6 \pm 2.7$ \\
Xihua & $1992-95 ; 1997-2001 ; 2003-04$ & $290.1 \pm 4.8$ & $285.1 \pm 6.5$ & $154.3 \pm 4.8$ & $152.9 \pm 2.1$ \\
Zhumadian & $1992-2013$ & $297 \pm 4.9$ & $292 \pm 5.4$ & $151.1 \pm 6.8$ & $144.4 \pm 4.5$ \\
Shangqiu & $1992-97 ; 1999-2013$ & $288.6 \pm 4.3$ & $286.3 \pm 2.4$ & $155.6 \pm 4.6$ & $150.7 \pm 3.1$ \\
Miyun & $2000-08 ; 2010-13$ & $281.7 \pm 3.6$ & $278.94 \pm 6.7$ & $167.6 \pm 4.0$ & $166.5 \pm 2.9$ \\
\hline
\end{tabular}




\section{Results}

\section{a. Maturity belts for summer corn in the NCP}

The spatial distribution of different maturity belts of summer corn based on the AAT10 over the period of 1961-2015 in the NCP is shown in Fig. 3. The AAT10 increased from north to south and ranged from $900.2^{\circ}$ to $3078.2^{\circ} \mathrm{C}$, with an average value of $2153.3^{\circ} \mathrm{C}$. Five maturity levels of summer corn, that is, from very early ripe to very late ripe, could all be planted in the NCP, accounting for approximately $80.6 \%$ of the entire study area. The northern boundary of the summer corn planting area was located in the middle of Beijing and bordered the Yan Mountains, and the northern region of the boundary in the NCP exhibited insufficient accumulated temperature for growing summer corn. Tianjin and central Shandong were suitable for planting early ripe summer corn with an AAT10 ranging from $2000^{\circ}$ to $2200^{\circ} \mathrm{C}$. Western Shandong and southern Hebei provided abundant thermal resources for mid- and late ripe summer corn, while very late ripe summer corn could be planted only in Henan. The dominant summer corn belts in the NCP included the midripe belt, late ripe belt, and very late ripe belt, with planting areas accounting for $20.7 \%, 25.6 \%$, and $19.7 \%$ of the total planting area, respectively.

\section{b. Variations in summer corn planting boundaries in the NCP}

Figure 4 illustrates the shift in the geographical planting boundaries of different summer corn maturity levels in three time periods, that is, P1 (1961-80; red lines), P2 (1981-2000; blue lines), and P3 (2001-15; green lines). The results showed that the planting boundaries of the five summer corn maturity belts all moved northward and eastward during the past 55 years. Compared with $\mathrm{P} 1$, the northern planting boundary of very early ripe and early ripe corn in P3 moved northward by approximately $25-100$ and $30-120 \mathrm{~km}$, respectively, and the largest northward trends were both found in Beijing (Figs. 4a,b). The eastern planting boundary of early ripe corn also moved constantly eastward, leading to the fact that early ripe summer corn could be planted in eastern Shandong in P3, but this area was not suitable for early ripe corn in P1. The planting boundary of the midripe corn showed both a larger northward and a larger eastward trend relative to that of the very early ripe and early ripe corn, which moved northward from central Hebei in P1 to central Beijing in $\mathrm{P} 3$, as well as eastward from central Shandong in P1 to eastern Shandong in P3 (Fig. 4c). A significant northward trend was found for the northern planting boundary of the late ripe corn in $\mathrm{P} 3$ compared to that in $\mathrm{P} 1$,

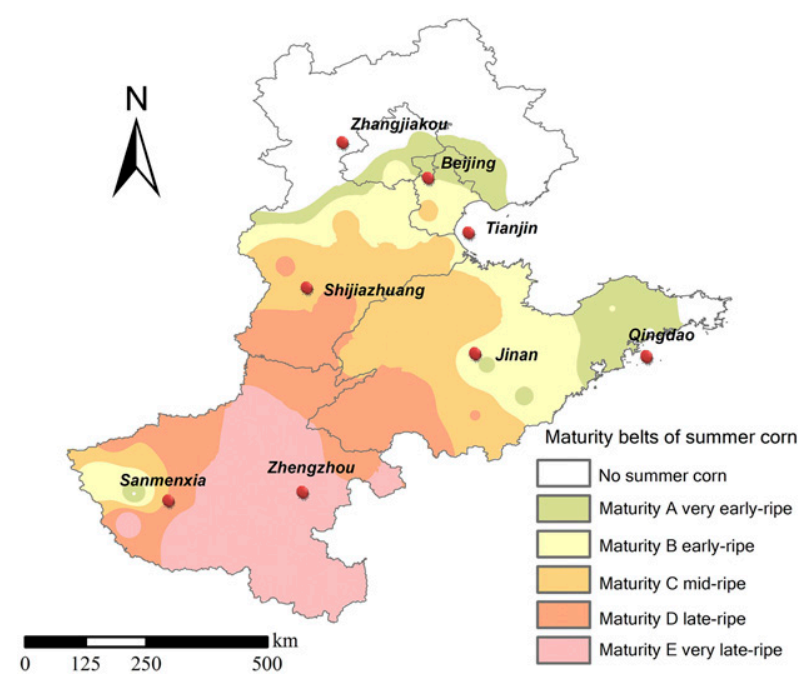

FIG. 3. Distribution of maturity belts of summer corn in the NCP in 1961-2015. A spatial distribution map was constructed using the inverse-distance-weighting interpolation method embedded in the ArcGIS 10.1 software package, and the spatial resolution was $0.02^{\circ}$ (approximately $2 \mathrm{~km}$ ). The same method was used for Figs. 4, 6, and 9 , below.

with a northward movement value of $2.2^{\circ}$ in latitude (Fig. 4d). Similar to late ripe corn, the maturity belts for very late ripe summer corn existed only in east Henan in P1, but in P3, it expanded to all of Henan as the boundary moved northward, as shown in Fig. 4e.

As the planting boundaries of different summer corn maturity levels have changed in the past 55 years, the possible planting area of each maturity belt of summer corn was also expected to change in the NCP, as shown in Table 3. A significant increasing trend for the planting area of the very late ripe belt was found in the study area, with the area increasing by $13.61 \times 10^{4} \mathrm{~km}^{2}$ in $\mathrm{P} 3$ relative to that of $\mathrm{P} 1$, leading to the finding that the very late ripe belt showed the largest area in P3. A decreasing area trend was found for the very early ripe belt, and the areas in $\mathrm{P} 2$ and $\mathrm{P} 3$ were $15.4 \%$ and $66.0 \%$ lower than those in P1, respectively. The change was because the northward movement of the northern planting boundary of the early ripe belt (approximately $30-120 \mathrm{~km}$ ) in P3 was greater than that for the very early ripe belt (25-100 km, as shown above). Similar results were also found for the early ripe belt, with the areas in P2 and P3 decreasing by $12.8 \%$ and $53.0 \%$, respectively, relative to that in P1. For the midripe belt and the late ripe belt, the planting area increased by $13.1 \%$ in $\mathrm{P} 2$ but decreased by $7.5 \%$ in $\mathrm{P} 3$ compared to that of $\mathrm{P} 1 . \mathrm{P} 2$ showed a greater northward movement in the northern planting boundary for the midripe belt than for that of the late ripe belt; in contrast, the northward movement of the northern planting boundary for the midripe belt was less than that 

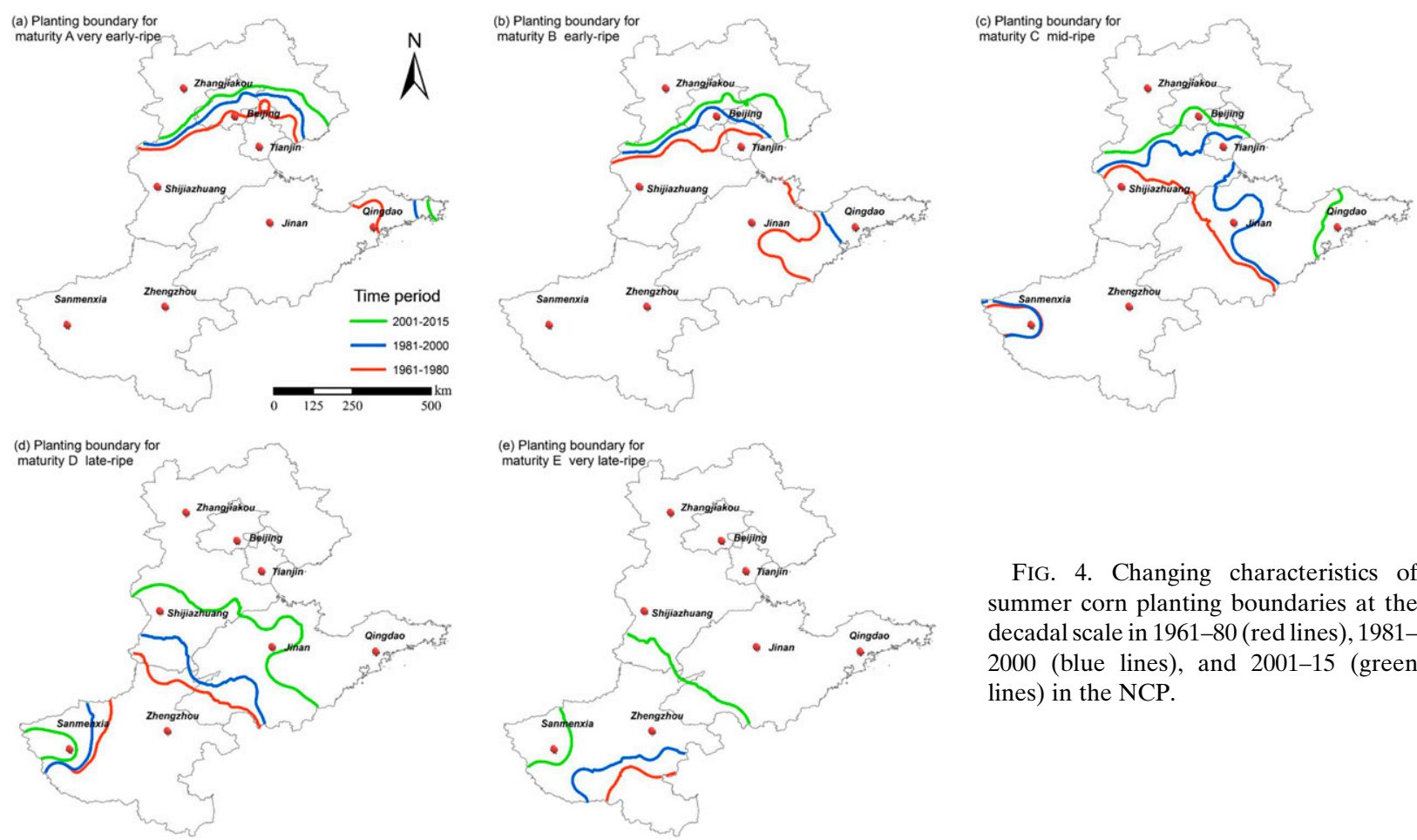

FIG. 4. Changing characteristics of summer corn planting boundaries at the decadal scale in 1961-80 (red lines), 19812000 (blue lines), and 2001-15 (green lines) in the NCP.

of the late ripe belt in P3. Overall, climate change has expanded the summer corn planting area in the NCP, and the total planting area of summer corn in P2 and P3 has increased by $2.95 \times 10^{4}$ and $3.66 \times 10^{4} \mathrm{~km}^{2}$ relative to that in $\mathrm{P} 1$, respectively.

\section{c. Analysis on the changing growth period and AAT10 in the NCP}

In essence, the changes in the maturity belts of summer corn in the NCP have resulted from the change in the AAT10 and growing season; therefore, the changing tendency of the AAT10 and growing days over the growth period of summer corn based on the long-term climate data was analyzed. The planting date of summer corn in the NCP indicate that the corn has significantly advanced by 3.4 days decade ${ }^{-1}(p<0.01$; purple curve in Fig. 5), indicating that winter wheat in the NCP could now be harvested earlier than in previous years because of climate warming. With regard to the physiological maturation date of summer corn, a significant delayed trend was found with a trend value of 2.4 days decade ${ }^{-1}$ $(p<0.01$; orange curve in Fig. 5$)$ in the study area. The growing season for summer corn in the NCP has been prolonged over the past 55 years, with an average trend value of 5.8 days decade $^{-1}$, which resulted from changes in the planting date and physiological maturation date. The results also indicated that the change in the planting date (advanced by 3.4 days) contributed more than did the physiological maturation date (delayed by 2.4 days).

The annual mean AAT10 during the summer corn growing season has increased by approximately $18.7 \%$ in the last 55 years, with an average trend value of $73.2^{\circ} \mathrm{C}$ decade $^{-1}$. The spatial distribution of the climatic trend rates of AAT10 during the summer corn growing period is shown in Fig. 6. The results showed that $94.9 \%$ of stations $(n=56)$ showed a significant increasing

TABLE 3. Change characteristics of the possible planting area of maturity belts for summer corn in the NCP.

\begin{tabular}{|c|c|c|c|c|c|c|}
\hline & Very early ripe belt & Early ripe belt & Midripe belt & Late ripe belt & Very late ripe belt & Total \\
\hline $\mathrm{P} 1\left(\times 10^{4} \mathrm{~km}^{2}\right)$ & 6.07 & 9.51 & 11.52 & 10.41 & 3.28 & 40.8 \\
\hline $\mathrm{P} 2\left(\times 10^{4} \mathrm{~km}^{2}\right)$ & 5.13 & 8.3 & 13.03 & 12.27 & 5.03 & 43.75 \\
\hline $\mathrm{P} 3\left(\times 10^{4} \mathrm{~km}^{2}\right)$ & 2.06 & 4.47 & 10.66 & 10.39 & 16.89 & 44.46 \\
\hline \multicolumn{7}{|c|}{ Percentage of changing area relative to $\mathrm{P} 1(\%)$} \\
\hline $\mathrm{P} 2$ & -15.4 & -12.8 & 13.1 & 17.8 & 53.1 & 7.2 \\
\hline $\mathrm{P} 3$ & -66.0 & -53.0 & -7.5 & -0.2 & 414.2 & 9.0 \\
\hline
\end{tabular}




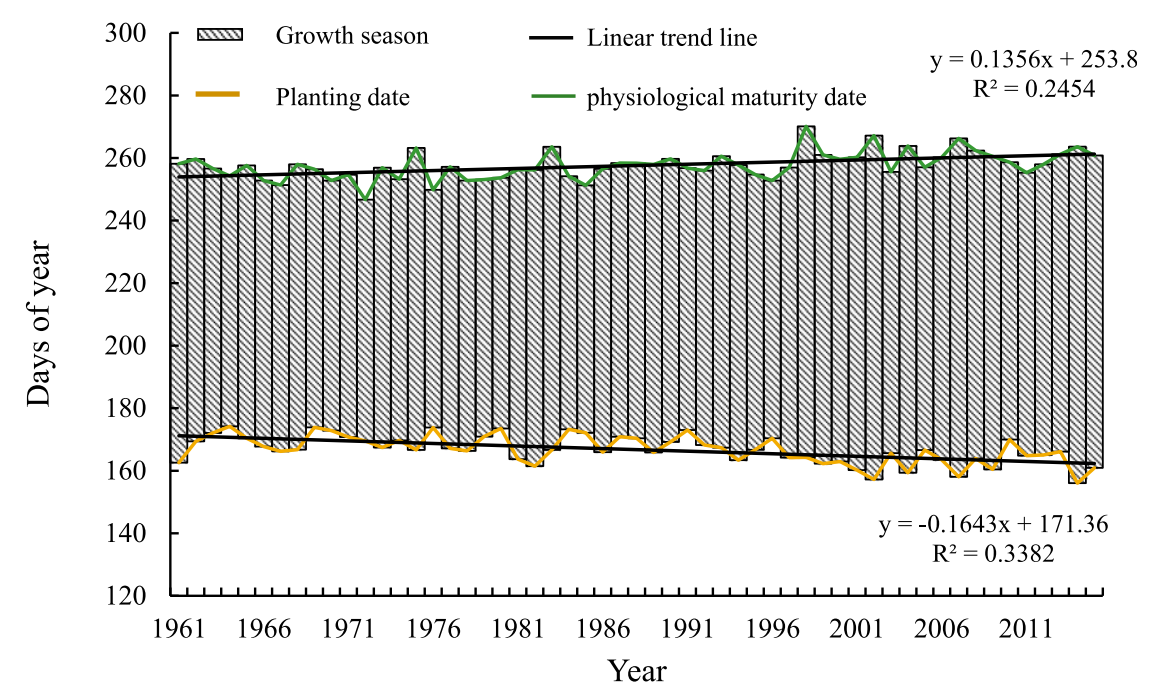

FIG. 5. Changes in planting date, physiological maturity date, and growth season for summer corn in the NCP in 1961-2015. The results indicated that the prolonged growth season resulted from changes in both the planting date and the physiological maturity date. The change in the planting date (advanced by 3.4 days decade ${ }^{-1}$ ) contributed more than did the physiological maturity date (delayed by 2.4 days decade ${ }^{-1}$ ).

trend at the $p<0.01$ level, with a trend value greater than $30^{\circ} \mathrm{C}$ decade $^{-1}$. The largest AAT10 increasing rate occurred in eastern Shandong, Beijing, and Tianjin, with trend values greater than $90^{\circ} \mathrm{C}$ decade $^{-1}$. West Shandong and South Hebei showed a smaller rate of increase of AAT10, with a trend value less than $60^{\circ} \mathrm{C}$ decade $^{-1}$.

The changes in the AAT10 may be caused by two factors, that is, DT10 and the average temperature for DT10, and they were both analyzed as shown in Fig. 7. A significant increasing trend was found for DT10 during the summer corn growth period (Fig. 7a), which has increased by 16.4 days over the last 55 years, with a trend value of 3.0 days decade ${ }^{-1}$. A $54.8 \%$ increase was contributed by the advanced planting date (trend value 1.64 days decade ${ }^{-1}$, as shown in Fig. 5) in the NCP, and another contribution was made by the number of days that were originally less than $10^{\circ} \mathrm{C}$ but are now greater than $10^{\circ} \mathrm{C}$ because of climate warming. For the average temperature of DT10, a nonsignificant changing trend was found during the study period. In summary, the increase in the AAT10 mainly resulted from the increased DT10 and was unrelated to the average temperature of DT10 (Fig. 7b).

\section{Discussion}

\section{a. Climate change pattern and corn responses}

The NCP has experienced a noticeable climate warming trend, and the trend value was 2 times as high as the value of the rate of increase of Earth's surface temperature reported by the IPCC. Moreover, the NCP is predicted to be the most significant climate warming region in China, as the magnitude of the temperature increase in the future 30 years will be greater than the mean for 1960-2000 (Liu et al. 2008). One negative impact of climate warming on crop yield is that, as revealed by many studies, higher temperatures could reduce the length of the growing period by accelerating crop development and maturation (Olesen and Bindi 2002). Meng et al. (2015)

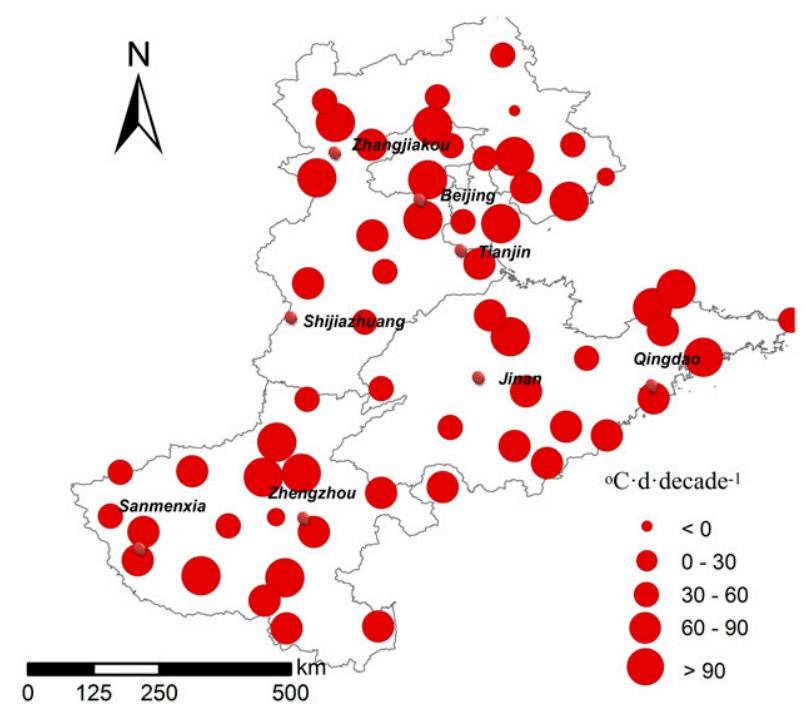

FIG. 6. Spatial distribution of the climatic trend rates of AAT10 during the summer corn growing season in the NCP. 

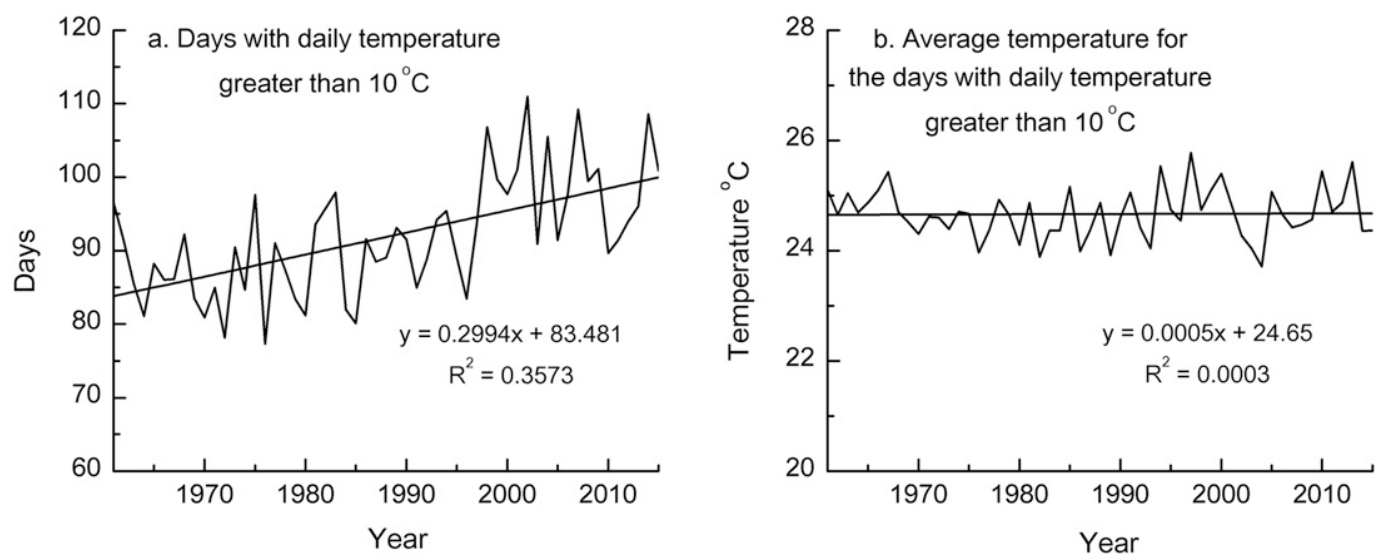

FIG. 7. Changes in (a) days with daily temperature greater than $10^{\circ} \mathrm{C}$ and (b) its average temperature for summer corn in the NCP in 1961-2015.

found that the growing period and reproductive growth of corn would be shortened by 2.71 and 1.07 days, respectively, when the average temperature was increased by $1^{\circ} \mathrm{C}$. The changes in growing season temperature found in this study indicate that the potential growing period of summer corn in the NCP has increased by 31.9 days in the past 55 years. This implies that if farmers take advantage of earlier planting along with using warmer season cultivars to lengthen the growing period, the corn yield decreases resulting from climate change might be mitigated. Previous studies have showed that earlier planting could obtain a higher yield in China ( $\mathrm{Li}$ et al. 2012), and a similar result was found in Iran by Peykarestan (2012). Liu et al. (2016) found that the summer corn yield in the NCP increased by 83.8$158.1 \mathrm{~kg} \mathrm{ha}^{-1}$ day $^{-1}$ when harvest was delayed by five days, and a greater impact was found on midlate ripe corn than on early ripe corn.

By obtaining more heat resources, new corn hybrids with a longer growing period are expected to produce higher yields (Torriani et al. 2007; Xiao et al. 2016). Z. Liu et al. (2013) reported that the corn yield of midripe corn was $9.8 \%$ higher than that of early ripe corn under the same climate and soil conditions; similarly, the corn yield increased by $7.1 \%$ when midripe corn was replaced by late ripe corn. Therefore, for the wheatcorn cropping system in the NCP (particularly in the northern region), a suitable variety and proper early sowing are needed to ensure high yields of summer maize, and the harvesting time should be delayed on the basis of not influencing wheat seeding. Here, we further explore the regional corn yield per unit area in the NCP in the past 35 years, as shown in Fig. 8. A significant increasing trend for corn yield per unit area was found with a trend value of $0.85 \mathrm{tha}^{-1}$ decade $^{-1}$, indicating that the NCP showed higher corn productivity in the context of climate change. Although the changes in corn productivity are known to be caused by many factors, such as variety, irrigation, and fertilization, climate warming as a whole exhibited a positive impact on the corn yield per unit area after detrending the agronomic technique contributions to the increments of corn productivity (Ma et al. 2008; Yang et al. 2015).

\section{b. Planting boundaries}

Because cropping patterns are mainly determined by heat resources, climate warming has greatly impacted the planting boundaries of different cropping systems. Previous studies have reported that the northern limits of the triple-cropping system in South China and the single-cropping system in Northeast China have both moved northward in the past 30 years (Yang et al. 2011; Z. Liu et al. 2013; Xia et al. 2014). In this study, we also found that in a wheat-corn double-cropping system in the NCP, the planting boundaries of summer corn shifted northward and eastward due to climate warming,

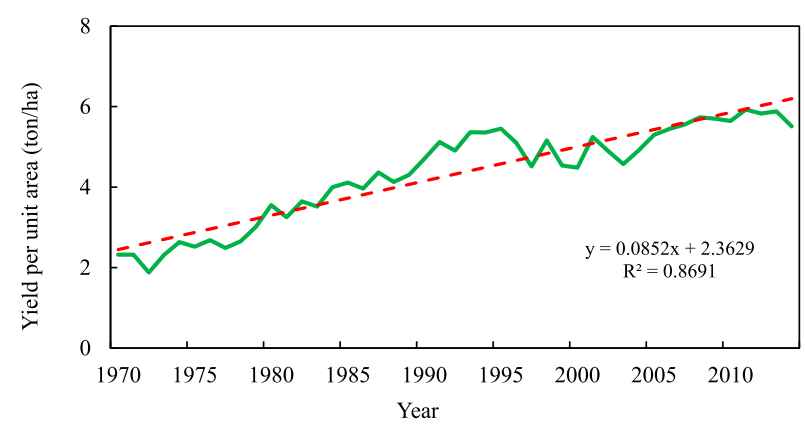

FIG. 8. Changes in corn yield per unit area $\left(\mathrm{t} \mathrm{ha}^{-1}\right)$ in the NCP from 1970 to 2015. The data were from the National Bureau of Statistics of the People's Republic of China (NBSPRC; http:// www.stats.gov.cn). 

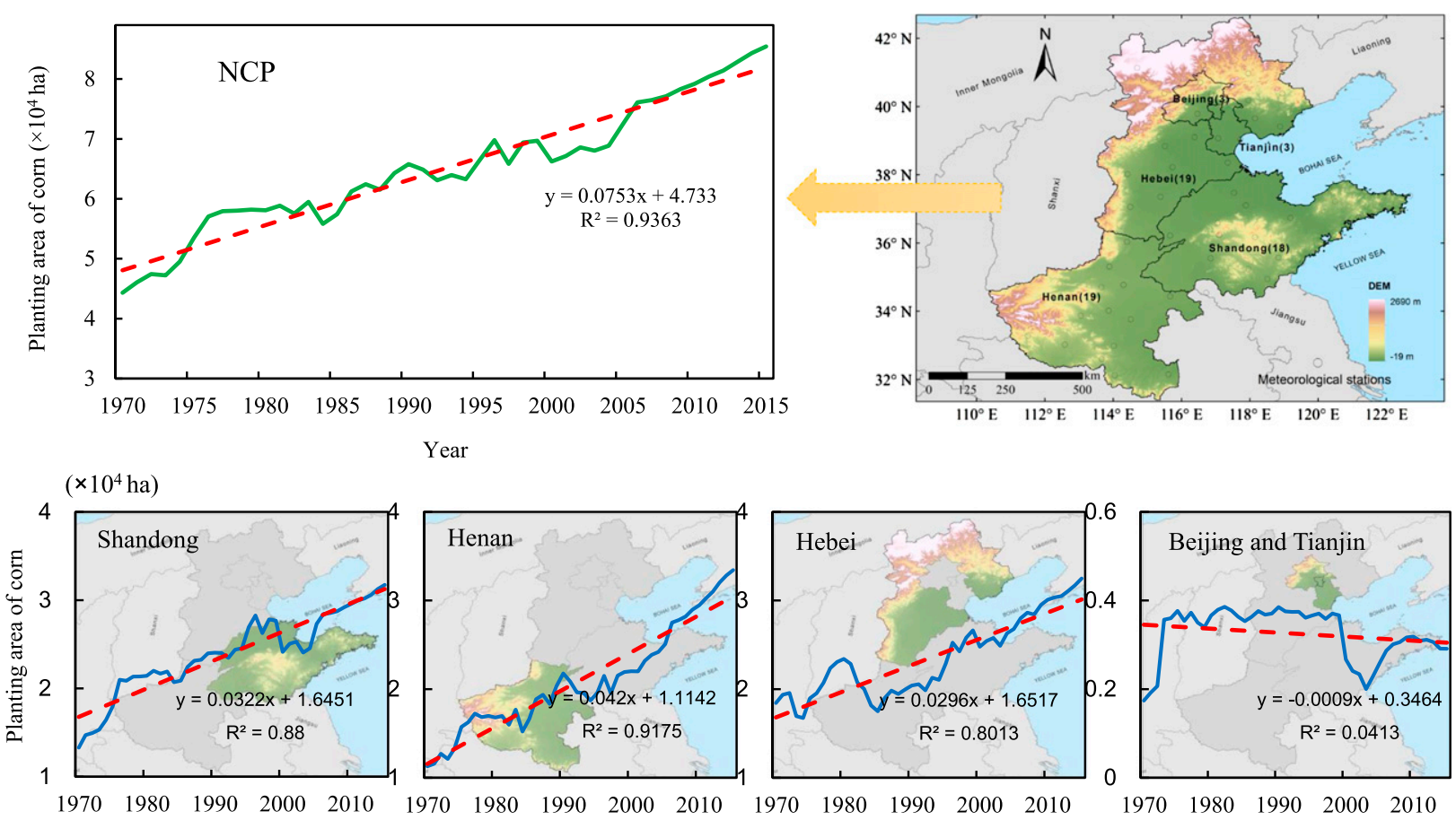

FIG. 9. Changes in the actual planting area of corn in the NCP from 1970 to 2015. The planting area of corn in three provinces (i.e., Hebei, Shandong, and Henan) and two province-level municipalities (i.e., Beijing and Tianjin, combined as one figure) is also shown in Fig. 9. The data were obtained from NBSPRC. Since the statistical data include the area of spring corn in northern Hebei, the planting area shown in the Fig. 9 is larger than the reality area for the corn-wheat cropping.

resulting in the expansion of the total potential planting area. It is important to note that we analyzed the changes in the planting boundaries of summer corn based only on the thermal time. Actual cropping systems are comprehensively influenced by many factors, such as soil conditions, precipitation, and social components (Yang et al. 2011), which should be considered in subsequent studies and practical applications. For example, a sustained growth of the actual corn planting area in the NCP from 1970 to 2015 was found (Fig. 9), and three major corn-producing regions (i.e., Hebei, Shandong, and Henan) all showed a significant positive trend in the size of the actual corn planting area. However, slight changes in the actual corn planting area were observed in Beijing and Tianjin because of the high urbanization rate.

\section{Conclusions}

By comprehensively considering the wheat-corn cropping system in the NCP, this study focused on the planting boundaries and possible cultivation areas of each maturity level of summer corn in the past 55 years. The NCP could cultivate all five maturity levels of summer corn, that is, from very early ripe to very late ripe corn. Midripe summer corn and late ripe summer corn were found to be the dominant summer corn belts, with a planting area that accounted for more than $20 \%$ of the total corn planting area in the NCP. The planting boundaries of the five corn maturity levels have all shifted northward and eastward due to climate warming, resulting in the expansion of the total planting area. The NCP showed a significant increasing planting area trend for the very late ripe belt of summer corn, with the area increasing by $13.61 \times 10^{4} \mathrm{~km}^{2}$ in $\mathrm{P} 3(2001-15)$ relative to that of P1 (1961-80). However, the very early ripe belt exhibited a decreasing trend in area because of the greater northern shift of the early ripe belt than that of the very early ripe belt, and similar results were also found for the early ripe belt. The northward expansion of the planting boundaries of corn was caused by changes in the AAT above $10^{\circ} \mathrm{C}$ (AAT10) and the corn growth season. The corn growing season in the NCP has been prolonged over the past 55 years, which resulted from the advanced planting date and delayed physiological maturation date. The AAT10 during the corn growing season also increased due to climate warming, with a trend value of $73.2^{\circ} \mathrm{C} \mathrm{decade}^{-1}$, which was mainly contributed by the increase in the number of days with a daily temperature over $10^{\circ} \mathrm{C}$. Overall, climate warming has greatly changed the planting boundaries of different maturity levels of summer corn in the NCP, which benefits corn production by 
increasing the planting area and prolonging the growth period.

Acknowledgments. This research was funded by the National Key Research and Development Project (Grants 2017YFD0300304, 2017YFD0300404, and 2016YFD0300106) and the National Natural Science Foundation of China (41271053). The funding agencies had no involvement in the study design, analysis interpretation, writing, or publication.

\section{REFERENCES}

Bai, Q., Z. Huo, S. Li, H. Du, N. He, and Y. Jiang, 2008: Comparison of accumulated temperature above $10^{\circ} \mathrm{C}$ before and after the year 1978 in China. Yingyong Shengtai Xuebao, 19, 1810-1816.

Bonfante, A., E. Monaco, S. M. Alfieri, F. D. Lorenzi, P. Manna, A. Basile, and J. Bouma, 2015: Climate change effects on the suitability of an agricultural area to maize cultivation: application of a new hybrid land evaluation system. Adv. Agron., 133, 33-69, https://doi.org/10.1016/bs.agron.2015.05.001.

Bu, L., X. Chen, S. Li, J. Liu, L. Zhu, S. Luo, R. L. Hill, and Y. Zhao, 2015: The effect of adapting cultivars on the water use efficiency of dryland maize (Zea mays L.) in northwestern China. Agric. Water Manage., 148, 1-9, https://doi.org/10.1016/ j.agwat.2014.09.010.

Bunting, E. S., 1976: Accumulated temperature and maize development in England. J. Agric. Sci., 87, 577-583, https://doi.org/ 10.1017/S0021859600033207.

_ 1979: The relationship between mean temperature and accumulated temperature totals for maize in the central lowlands of England. J. Agric. Sci., 93, 157-169, https://doi.org/ 10.1017/S002185960008624X.

Chen, C., E. Wang, and Q. Yu, 2010: Modeling wheat and maize productivity as affected by climate variation and irrigation supply in North China Plain. Agron. J., 102, 1037-1049, https:// doi.org/10.2134/agronj2009.0505.

Chen, H., 2012: Temporal and spatial variations of sunshine duration and its influence factors in the north China plain in recent 50 years. J. Meteor. Sci., 32, 573-579.

Chen, X., 2017: Contributions of climate change and human activities to ET and GPP trends over North China Plain from 2000 to 2014. J. Geogr. Sci., 27, 661-680, https://doi.org/ 10.1007/s11442-017-1399-z.

Chezik, K. A., N. P. Lester, and P. A. Venturelli, 2014: Fish growth and degree-days II: Selecting a base temperature for an among-population study. Can. J. Fish. Aquat. Sci., 71, 13031311, https://doi.org/10.1139/cjfas-2013-0615.

Cui, Z., X. Chen, and F. Zhang, 2010: Current nitrogen management status and measures to improve the intensive wheatmaize system in China. Ambio, 39, 376-384, https://doi.org/ 10.1007/s13280-010-0076-6.

Dong, J., J. Liu, F. Tao, X. Xu, and J. Wang, 2009: Spatio-temporal changes in annual accumulated temperature in China and the effects on cropping systems, 1980s to 2000. Climate Res., 40, 37-48, https://doi.org/10.3354/cr00823.

Easterling, W. E., C. J. Hays, M. K. Easterling, and J. R. Brandle, 1997: Modelling the effect of shelterbelts on maize productivity under climate change: An application of the epic model. Agric. Ecosyst. Environ., 61, 163-176, https://doi.org/ 10.1016/S0167-8809(96)01098-5.
Fang, H., and Coauthors, 2010: Study on the growth period of maize varieties in China (in Chinese with English abstract). J. Hebei Agric. Sci., 14, 1-5.

Harrison, L., J. Michaelsen, C. Funk, and G. Husak, 2011: Effects of temperature changes on maize production in Mozambique. Climate Res., 46, 211, https://doi.org/10.3354/cr00979.

He, P., S. Li, J. Jin, C. Li, Y. Wang, and R. Cui, 2009: Performance of an optimized nutrient management system for double-cropped wheat-maize rotations in north-central China. Agron. J., 101, 1489-1496, https://doi.org/10.2134/agronj2009.0099.

Hou, P., Y. Liu, R. Xie, M. Bo, D. Ma, S. Li, and X. Mei, 2014: Temporal and spatial variation in accumulated temperature requirements of maize. Field Crops Res., 158, 55-64, https:// doi.org/10.1016/j.fcr.2013.12.021.

Hu, Q., X. Pan, C. Shao, D. Zhang, X. Wang, and X.-Y. Wei, 2014: Distribution and variation of China agricultural heat resources in 1961-2010. Zhonghua Nongye Qixiang, 35, 119-127.

Huang, J., F. Zhang, Y. Xue, and J. Lin, 2016: Recent changes of rice heat stress in Jiangxi province, southeast China. Int. J. Biometeor., 61, 623-633, https://doi.org/10.1007/s00484-0161239-3.

IPCC, 2013: Climate Change 2013: The Physical Science Basis. Cambridge University Press, 1535 pp., https://doi.org/10.1017/ CBO9781107415324.

Jin, Z. Q., D. K. Ge, C. L. Shi, and L. Z. Gao, 2002: Several strategies of food crop production in the Northeast China Plain for adaptation to global climate change: a modeling study. Zuowu Xuebao, 28, 24-31.

Kreuzer, A. M., W. Aeschbach-Hertig, and C. Zongyu, 2004: Environmental tracers in groundwater of the North China Plain. Nanshui Beidiao Yu Shuili Keji, 11, 82-85.

Li, Q., L. Nian, W. Liu, L. Li, S. M. Zhou, and J. Yin, 2010: Effects of accumulated temperature before winter on growth and development of wheat in Henan province. Zhonghua Nongye Qixiang, 31, 563-569.

_ L. Li, J. Niu, and J. Yin, 2012: Temperature impacts on wheat growth and yield in the North China Plain. Afr. J. Biotechnol., 37, 8992-9000, https://doi.org/10.5897/AJB11.4152.

Li, X., C. Hu, J. A. Delgado, Y. Zhang, and Z. Ouyang, 2007: Increased nitrogen use efficiencies as a key mitigation alternative to reduce nitrate leaching in north China plain. Agric. Water Manage., 89, 137-147, https://doi.org/10.1016/j.agwat.2006.12.012.

Liu, S., C. Jia, S. Tang, Z. Sun, J. Yang, S. Dong, and J. Liu, 2016: Effects of late harvest on yield of summer maize with different mature periods. Shandong Agric. Sci., 48, 36-39.

Liu, Y., J. Yan, T. Wu, Y. Guo, L. Chen, and J. Wang, 2008: Prediction research of climate change trends over North China in the future 30 years. Acta Meteor. Sin., 22, 42-50.

—, P. Hou, R. Xie, S. Li, H. Zhang, B. Ming, D. Ma, and S. Liang, 2013: Spatial adaptabilities of spring maize to variation of climatic conditions. Crop Sci., 53, 1693-1703, https://doi.org/ 10.2135/cropsci2012.12.0688.

Liu, Z., E. Wang, X. Yang, and W. Jing, 2010: Contributions of climatic and crop varietal changes to crop production in the North China Plain, since 1980s. Global Change Biol., 16, 2287 2299, https://doi.org/10.1111/j.1365-2486.2009.02077.x.

— K. G. Hubbard, X. Lin, and X. Yang, 2013: Negative effects of climate warming on maize yield are reserved by the changing of sowing date and cultivar selection in Northeast China. Global Change Biol., 19, 3481-3492, https://doi.org/10.1111/GCB.12324.

Lobell, D. B., W. Schlenker, and J. Costa-Robert, 2011: Climate trends and global crop production since 1980. Science, 333, 616-620, https://doi.org/10.1126/science.1204531. 
Luo, X., J. Xia, and H. Yang, 2015: Modeling water requirements of major crops and their responses to climate change in the North China Plain. Environ. Earth Sci., 74, 3531-3541, https:// doi.org/10.1007/s12665-015-4400-0.

Ma, S., Q. Wang, and X. Luo, 2008: Effect of climate change on maize (Zea mays) growth and yield based on stage sowing. Acta Ecol. Sin., 28, 2131-2139.

McMaster, G. S., and W. W. Wilhelm, 1998: Is soil temperature better than air temperature for predicting winter wheat phenology. Agron. J., 90, 602-607, https://doi.org/10.2134/ agronj1998.00021962009000050006x.

Meng, L., X. J. Liu, W. U. Dingrong, and C. Y. Wang, 2015: Responses of summer maize main phenology to climate change in the North China Plain. Zhonghua Nongye Qixiang, 36, $375-382$.

Murakami, T., Y. Doi, and H. Morita, 2009: Relation between the accumulated temperature in effective degrees and the ripening of rice. Chemosphere, 77, 625-630.

Olesen, J. E., and M. Bindi, 2002: Consequences of climate change for European agricultural productivity, land use and policy. Eur. J. Agron., 16, 239-262, https://doi.org/10.1016/S11610301(02)00004-7.

— crop production systems to climate change. Eur. J. Agron., 34, 96-112, https://doi.org/10.1016/j.eja.2010.11.003.

Parry, M. L., C. Rosenzweig, A. Iglesias, M. Livermore, and G. Fischer, 2004: Effects of climate change on global food production under SRES emissions and socio-economic scenarios. Global Environ. Change, 14, 53-67, https://doi.org/ 10.1016/j.gloenvcha.2003.10.008.

Peykarestan, B., 2012: Sowing date effect on growth and yield attributes of corn (Zea mays everta sturt) grown under different densities. Afr. J. Agric. Res., 7, 4427-4431.

Porter, J. R., 2005: Rising temperatures are likely to reduce crop yields. Nature, 436, 174, https://doi.org/10.1038/436174b.

Rötter, R., and S. C. van de Geijn, 1999: Climate change effects on plant growth, crop yield and livestock. Climatic Change, $\mathbf{4 3}$, 651-681, https://doi.org/10.1023/A:1005541132734.

Schoenau, G. J., and R. A. Kehrig, 1990: Method for calculating degree-days to any base temperature. Energy Build., 14, 299-302, https://doi.org/10.1016/0378-7788(90)90092-W.

Siebert, S., F. Ewert, E. Eyshi Rezaei, H. Kage, and R. Graß, 2014: Impact of heat stress on crop yield-On the importance of considering canopy temperature. Environ. Res. Lett., 9, 044012, https://doi.org/10.1088/1748-9326/9/4/044012.

Sprague, G. F., and J. W. Dudley, Eds., 1988: Corn and Corn Improvement. 3rd ed. Agronomy Monogr., No. 18, American Society of Agronomy, 986 pp.

Tao, F., and Z. Zhang, 2010: Adaptation of maize production to climate change in North China Plain: quantify the relative contributions of adaptation options. Eur. J. Agron., 33, 103 116, https://doi.org/10.1016/j.eja.2010.04.002.

_-, M. Yokozawa, Y. Xu, Y. Hayashi, and Z. Zhang, 2006: Climate changes and trends in phenology and yields of field crops in China, 1981-2000. Agric. Meteor., 138, 82-92, https://doi.org/ 10.1016/j.agrformet.2006.03.014.
Todd, C. M., 1996: Temperature threshold for growth and temperature-dependent weight gain of field-collected Tipula montana. Eur. J. Entomol., 93, 185-194.

Torriani, D. S., P. Calanca, S. Schmid, M. Beniston, and J. Fuhrer, 2007: Potential effects of changes in mean climate and climate variability on the yield of winter and spring crops in Switzerland. Climate Res., 34, 59-69, https://doi.org/10.3354/cr034059.

Vaughan, D. G., and Coauthors, 2003: Recent rapid regional climate warming on the Antarctic Peninsula. Climatic Change, 60, 243-274, https://doi.org/10.1023/A:1026021217991.

Wang, J., E. Wang, X. Yang, F. Zhang, and H. Yin, 2012: Increased yield potential of wheat-maize cropping system in the North China plain by climate change adaptation. Climatic Change, 113, 825-840, https://doi.org/10.1007/s10584-011-0385-1.

Wang, Y., 2009: A primary research on the balanced fertilizer in interplanting corn with wheat. Zhongguo Nongxue Tongbao, 25, 144-146.

Xia, T., W. Wu, Q. Zhou, Q. Yu, P. H. Verburg, P. Yang, Z.-J. Lu, and H.-J. Tang, 2014: Spatio-temporal changes in the rice planting area and their relationship to climate change in Northeast China: A model-based analysis. J. Integr. Agric., 13, 1575-1585, https://doi.org/10.1016/S2095-3119(14)60802-9.

Xiao, D., and F. Tao, 2016: Contributions of cultivar shift, management practice and climate change to maize yield in North China Plain in 1981-2009. Int. J. Biometeor., 60, 1111-1122, https://doi.org/10.1007/s00484-015-1104-9.

_ Coauthors, 2016: Impact of warming climate and cultivar change on maize phenology in the last three decades in North China Plain. Theor. Appl. Climatol., 124, 653-661, https:// doi.org/10.1007/s00704-015-1450-x.

Yang, H., C. Xu, C. Li, and F. Li, 2009: Growth and required accumulated temperature of winter wheat under different sowing time. Zhonghua Nongye Qixiang, 30, 201-203.

Yang, X., Z. Liu, and F. Chen, 2011: The possible effect of climate warming on northern limits of cropping system and crop yield in China. Agric. Sci. China, 10, 585-594, https://doi.org/ 10.1016/S1671-2927(11)60040-0.

- Coauthors, 2015: Potential benefits of climate change for crop productivity in China. Agric. For. Meteor., 208, 76-84, https:// doi.org/10.1016/j.agrformet.2015.04.024.

Yi, J., H. Liang, and P. Wang, 2013: Effects of climate warming on the planting boundary and developmental stages of winter wheat. Mailei Zuowu Xuebao, 33, 382-388.

Yun, Y., X. Fang, Y. Wang, J. Tao, and D. Qiao, 2005: Main grain crops structural change and its climate background in Heilongjiang province during the past two decades. Ziran Ziyuan Xuebao, 20, 697-705.

Zhang, X., S. Chen, M. Liu, D. Pei, and H. Sun, 2005: Improved water use efficiency associated with cultivars and agronomic management in the North China Plain. Agron. J., 97, 783-790, https://doi.org/10.2134/agronj2004.0194.

Zhang, Z., X. Song, F. Tao, S. Zhang, and W. Shi, 2016: Climate trends and crop production in China at county scale, 1980 to 2008. Theor. Appl. Climatol., 123, 291-302, https://doi.org/ 10.1007/s00704-014-1343-4. 